\title{
Bio-paraffin from Soybean Oil as Eco-friendly Alternative to Mineral Waxes
}

\author{
Sandra Romero, Roque J. Minari, and Sebastián E. Collins* \\ Cite This: Ind. Eng. Chem. Res. 2021, 60, 5364-5373 \\ Read Online
}

ABSTRACT: Blends of fully and partial hydrogenated soybean oil, with 50/50 and $80 / 20$ wt $\%$, were chemically interesterified. The composition-texture relationships were investigated and established for the set of investigated materials. The raw materials, the original and interesterified blends, were analyzed in terms of their fatty acid and triacylglycerol compositions by gas chromatography. All materials were characterized by differential scanning calorimetry (DSC), polymorphic forms were characterized by X-ray diffraction (XRD), crystalline structures were characterized by polarized light microscopy (PLM), and textures were characterized by penetration testing. Interesterification caused a rearrangement of triacylglycerol species, reducing the concentration of trisaturated, triunsaturated, and diunsaturated triacylglycerols, increasing the amount of monounsaturated triacylglycerol, and resulting in a lowering of

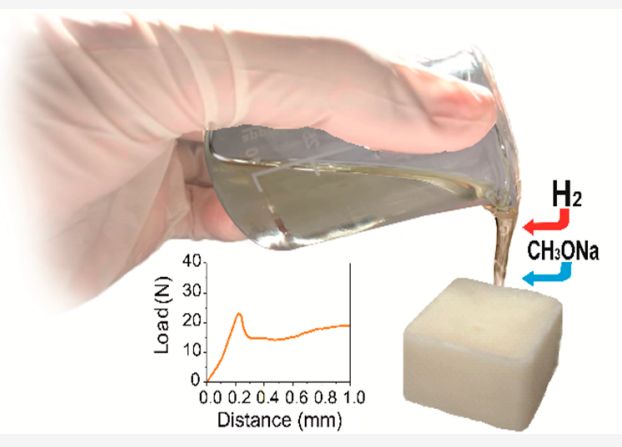
melting points as compared with the original blends. This modification in the chemical composition clearly changed the crystallization behavior, producing reductions in crystal size, alterations in crystalline polymorphism, and increases in plasticity in the blends. Interesterified materials displayed melting and textural characteristics suited for potential mineral wax substitutes.

\section{INTRODUCTION}

Paraffins, also known as mineral waxes, are natural waxes traditionally derived from petroleum which contain a mixture of different alkanes with a broad range of chain lengths between 18 and 60 carbon atoms. They present solid consistency at room temperature and are classified by their degrees according to their melting points, commonly between 40 and $90{ }^{\circ} \mathrm{C}$. ${ }^{1}$ The most characteristic properties of paraffins are melting profile, heat stability, hardness, consistency at room temperature, and clarity. ${ }^{2}$ These properties make them products with high demand for many applications such as manufacture of matches, candles, papers, adhesives, paints, pharmaceuticals, and cosmetics. ${ }^{3}$ However, as a petroleumbased material, paraffins are not sustainable or biodegradable. For these reasons, continuous searches for green-produced, biodegradable, and sustainable substitutes for fossil paraffins are performed. In this regard, vegetable oils appear as good raw materials to meet these requirements. As a commodity, some vegetable oils are accessible worldwide and produced in millions of tons. Thus, modified vegetable oils have been studied for the production of bio-paraffins to substitute for fossil waxes. Vegetable oils are mainly triacylglycerols (TAGs) that possess several highly reactive sites from which a wide variety of products with different structures and functionalities can be originated. ${ }^{4}$ In particular, soybean and palm oils, the most abundant vegetable oils in the world, are widely used for the production of biodiesel and further have been used as starting materials for the production of surfactants, ${ }^{5}$ lubricants, ${ }^{6}$ coatings, ${ }^{7}$ and resins. ${ }^{8,9}$
Bio-paraffins based on vegetable oil TAGs are typically obtained by modifying the composition of fatty acids through hydrogenation reaction, in order to raise their melting points. ${ }^{10}$ However, complete hydrogenation produces a rigid and bright material. Thus, some additional chemical modifications must be performed to match the desired properties, such as plasticity. ${ }^{11}$ Wang et al. ${ }^{12}$ incorporated, in partially hydrogenated soybean oil, hydroxyl groups and branched chains of short-chain fatty acids by epoxidation, ring opening, and esterification to improve cohesion, but the obtained materials have significantly lower hardness values and melting points than commercial paraffins. Yao et al. ${ }^{13}$ incorporated acetyl and hydroxy groups and long-chain fatty alcohol in fully hydrogenated soybean oil (FH) and identified possible paraffin substitutes for its use in packaging and coating products. More recently, Fei et al. ${ }^{2}$ synthesized, from saturated free fatty acids derived from $\mathrm{FH}$, monoesters and diesters with alcohols of different chain lengths and functional groups. Two possible paraffin substitutes for coatings were identified, through improving their properties by mixing with mineral paraffin. The above strategies involve multiple stages, making it difficult

Received: January 22, 2021

Revised: March 28, 2021

Accepted: March 30, 2021

Published: April 12, 2021 
to scale up and, more importantly, with a low atom efficiency and low green manufacture, due to only a partial substitution of mineral waxes was it achieved. Thus, additional efforts are needed to improve the performance of synthetic bio-paraffins to be employed in specific applications and to optimize the production process, that is, increase energy efficiency to achieve a sustainable process.

Nowadays, no ideal biorenewable material has been identified as replacement of petroleum-based paraffin, and therefore, there is a need to determine and evaluate more practical methods for lipid modification. A simpler strategy involves interestification reaction of mixed TAGs from different sources. The manufacture of "trans-free margarine" is commercially performed by interesterification of blends fats and oils from different sources. ${ }^{14-17}$ However, to the best of our knowledge, no studies have been reported in the literature that use interesterification of (partially) hydrogenated vegetable oils to obtain green substitutes to mineral waxes. Moreover, the understanding of the relationships between structure and property is still very limited, resulting in the study of these interactions being of high importance to obtain bio-paraffins with prespecified characteristics that the industrial sector demands.

In this scenario, this work pursues the development of a facile synthesis route of bio-paraffins from (partially) hydrogenated soybean oil, with properties suitable for their use in a variety of industrial applications. Binary mixtures of fully and partially hydrogenated soybean oil were chemically interesterified using sodium methoxide. The obtained bio-paraffins were characterized in composition by gas chromatography, and in physical properties by differential scanning calorimetry, X-ray diffraction, polarized light microscopy, and penetration testing. The synthesized biomaterials are compared with two commercial paraffins as reference.

\section{MATERIALS AND METHODS}

2.1. Materials. Refined soybean oil (SO) was kindly donated from Colibri Soybean Oil Producer (Santa Fe, Argentina). Hydrogenation of SO samples was carried out with a commercial nickel-based catalyst (Pricat 9910) on a "dead-end" batch reactor (Parr model 4522) with a total volume of $2000 \mathrm{~mL}$. The reaction was carried out at $140{ }^{\circ} \mathrm{C}$ with pure $\mathrm{H}_{2}(99.999 \%)$ at a constant pressure of 4 bar with stirring at $1500 \mathrm{rpm}$, and $0.15 \mathrm{wt} \%$ catalyst was used. ${ }^{18}$ A mass flow controller was employed to register the amount of hydrogen consumed.

Fully and partially hydrogenated soybean oil materials are named $\mathrm{FH}$ and $\mathrm{PH}$, respectively. Blended samples were prepared by melting different fractions of each original material at $100{ }^{\circ} \mathrm{C}$ and maintained at this temperature for $10 \mathrm{~min}$ to eliminate any crystalline history; then they were cooled to room temperature and stored in the dark at $5{ }^{\circ} \mathrm{C}$. The prepared blends were $\mathrm{FH} / \mathrm{PH}=50 / 50$ and 80/20 wt \%. Mixed samples were submitted to a chemical interesterification reaction using sodium methoxide. ${ }^{15}$ Reaction was performed with a three-necked spherical Pyrex glass reactor, magnetically stirred, and heated with an electric jacket connected to a temperature controller. The glass reactor was connected to a vacuum pump with a condensation trap. In a typical reaction, $300 \mathrm{~g}$ of a blended sample was dried in situ at $90{ }^{\circ} \mathrm{C}$ under dynamic vacuum. Next, the interesterification reaction was carried out at $90{ }^{\circ} \mathrm{C}$ for $30 \mathrm{~min}$ using a 0.4 wt \% sodium methoxide-30 wt \% methanol solution (Evonik Degussa
$\mathrm{GmbH})$. The reactor was continually purged with pure nitrogen $(25 \mathrm{~mL} / \mathrm{min})$ to avoid the inlet of atmospheric moisture. To finish the reaction, $5 \% \mathrm{v} / \mathrm{v}$ citric acid solution was added and then washed with water. The residual water was removed by drying under vacuum at $80{ }^{\circ} \mathrm{C}$. Both raw and blend materials were conserved under nitrogen atmosphere in darkness at $5{ }^{\circ} \mathrm{C}$.

Two commercial paraffins were employed as reference materials; they are identified as paraffin 62 and paraffin 72 according to their melting points of 62 and $72{ }^{\circ} \mathrm{C}$, respectively.

2.2. Characterization. The degree of hydrogenation of the investigated materials was determined by iodine value (IV) according to AOCS Official Method Cd 1-25. ${ }^{19}$

Analyses of fatty acid (FA) compositions of the obtained samples were performed in a Clarus 500 (PerkinElmer, USA) gas chromatograph (GC), after their methyl ester formation (FAME), by AOCS Official Method Ce 2-66. ${ }^{19}$ The identification and quantification of FAME was performed by using a capillary column Chrompack CP Sil 88 (50 m $\times 0.25$ $\mathrm{mm}$ internal diameter and $0.1 \mu \mathrm{m}$ film thickness). For this purpose, the injector was used in split mode with a ratio of $1: 50,1 \mu \mathrm{L}$ of solution was injected, the oven temperature was $200{ }^{\circ} \mathrm{C}$, the temperature of the injector and the FID was 220 ${ }^{\circ} \mathrm{C}$, and the carrier $\mathrm{H}_{2}$ gas flow was $1 \mathrm{~mL} / \mathrm{min}$. The quantitative composition was obtained by area normalization and was expressed as a percentage of mass, according to AOCS Official Method Ce 1f-96. ${ }^{19}$ Palmitic acid (P) C16:0, stearic acid (S) 18:0, oleic acid (O) C18:1, linoleic acid (L) C18:2, and linolenic acid ( $\mathrm{Ln}) \mathrm{C} 18: 3$, were quantified.

Triacylglycerol (TAG) composition was also analyzed by GC with an Agilent WCOT UltiMetal CP-TAP CB column $(25 \mathrm{~m} \times 0.25 \mathrm{~mm} \times 0.1 \mu \mathrm{m})$, which provides a resolution that depends on the number of carbons and the degree of unsaturation. The injector was used in split mode with a ratio of $1: 25 ; 1 \mu \mathrm{L}$ of solution was injected. The oven temperature was programmed using a temperature ramp of 5 ${ }^{\circ} \mathrm{C} / \mathrm{min}$ from 250 to $345{ }^{\circ} \mathrm{C}$ and held for $20 \mathrm{~min}$. The injector temperature was $340^{\circ} \mathrm{C}$, and the FID temperature was $370{ }^{\circ} \mathrm{C}$. The carrier $\mathrm{H}_{2}$ gas flow of $1 \mathrm{~mL} / \mathrm{min}$. Triacylglycerol species were quantified by their relative response factors of available standards and following the procedure described by Pacheco and co-workers: ${ }^{20} \mathrm{PPP}$, tripalmitoyl-glycerol (tripalmitin); SSS, tristearoyl-glycerol (tristearin); OOO, trioleoyl-glycerol (triolein); LLL, trilinoleoyl-glycerol (trilinolein). The TAGs quantified were the following: SSS, OOO, and PPS, 1,2dipalmitoyl-3-stearoyl-glycerol; POP, 1,3-dipalmitoyl-2-oleoylglycerol; PSS, 1-palmitoyl-2,3-distearoyl-glycerol; POS, 1palmitoyl-2-oleoyl-3-stearoyl-glycerol; POO, 1-palmitoyl-2,3dioleoyl-glycerol; SOS, 2-oleoyl-1,3-distearoyl-glycerol; SSO, 1-oleoyl-2,3-distearoyl-glycerol; SOO, 1-stearoyl-2,3-dioleoylglycerol.

Thermal analysis of the samples was performed with differential scanning calorimetry (DSC) according to AOCS Official Method Cj 1-94. ${ }^{19}$ A DSC Q2000 (TA Instruments) instrument was employed. Samples of 5-8 mg were weighed and placed in aluminum capsules (TZero). Nitrogen was used as a purging gas at a flow rate of $50 \mathrm{~mL} / \mathrm{min}$. Analysis was performed using the following temperature program: (i) heating to $80{ }^{\circ} \mathrm{C}$ and held for $10 \mathrm{~min}$; (ii) cooling from 80 to $-60{ }^{\circ} \mathrm{C}$ at $10^{\circ} \mathrm{C} / \mathrm{min}$ and held at $60{ }^{\circ} \mathrm{C}$ for $30 \mathrm{~min}$; (iii) heating from -60 to $80{ }^{\circ} \mathrm{C}$ at $5{ }^{\circ} \mathrm{C} / \mathrm{min}$.

The X-ray diffraction patterns were determined according to AOCS Official Method Cj 2-95. ${ }^{19}$ The analyses were 
performed on an XD-D1 diffractometer (Shimadzu), with $\mathrm{Cu}$ $\mathrm{K} \alpha$ radiation $(\lambda=1.54 \AA$, at $40 \mathrm{kV}$ and $30 \mathrm{~mA})$. Measurements were performed at $25{ }^{\circ} \mathrm{C}$, from 15 to $30^{\circ}$ ( $2 \theta$ scale) with a scanning speed of $1 \% \mathrm{~min}$. The samples were melted at approximately $80{ }^{\circ} \mathrm{C}$ and stabilized at $25{ }^{\circ} \mathrm{C}$ for $24 \mathrm{~h}$ before being analyzed. Polymorphic forms were identified from characteristic crystal spacings. $^{10}$

The microstructure was analyzed by polarized light microscopy (PLM). The samples were melted at $70{ }^{\circ} \mathrm{C}$, and with the help of a capillary tube, a drop was placed on a glass slide at the same temperature; then the covered slide was placed on the drop of sample to remove air and spread. The slides were kept at the analysis temperature $\left(25^{\circ} \mathrm{C}\right)$ for $24 \mathrm{~h}^{21}$ The crystal morphology was examined with a polarized light microscope (Zeiss Universal M) with an objective lens of $40 \times$. Each sample was prepared in duplicate, and at least five images were captured for each one.

The hardness and cohesiveness of the materials were determined by the penetration test by using a universal testing machine (INSTRON 3344) with a $2 \mathrm{~mm}$ flat-tip cylindrical indenter. Samples were prepared by melting them at $80{ }^{\circ} \mathrm{C}$ for $10 \mathrm{~min}$ and crystallizing them in molds $(2.5 \times 2.5 \times 2 \mathrm{~cm})$ at $25{ }^{\circ} \mathrm{C}$ for $3 \mathrm{~h}$. The tests were performed at a speed of $10 \mathrm{~mm} /$ min with a $1000 \mathrm{~N}$ load cell under controlled conditions of temperature and humidity $\left(25^{\circ} \mathrm{C}\right.$ and $50 \%$, respectively).

\section{RESULTS}

3.1. Chemical Composition. Table 1 shows the iodine values (IV) and the fatty acid compositions of the investigated

Table 1. Iodine Value and Fatty Acid Composition of the Investigated Materials $^{a}$

\begin{tabular}{|c|c|c|c|c|c|}
\hline & \multicolumn{5}{|c|}{ sample } \\
\hline & $\mathrm{SO}$ & $\mathrm{PH}$ & FH & $50 / 50$ & $80 / 20$ \\
\hline IV $\left(\mathrm{g}\right.$ of $\left.\mathrm{I}_{2} / 100 \mathrm{~g}\right)$ & 129 & 33.1 & 3.5 & 18.3 & 9.4 \\
\hline $16: 0(\%)$ & 10.6 & 11.0 & 10.3 & 10.7 & 10.4 \\
\hline 18:0 (\%) & 4.5 & 49.5 & 88.2 & 68.9 & 80.5 \\
\hline $18: 1(\%)$ & 24.0 & 39.4 & 1.5 & 20.4 & 9.1 \\
\hline $18: 2(\%)$ & 55.8 & - & - & - & - \\
\hline $18: 3(\%)$ & 5.2 & - & - & - & - \\
\hline
\end{tabular}

${ }^{a} 16: 0=$ palmitic acid $(\mathrm{P}), 18: 0=$ stearic acid $(\mathrm{S}), 18: 1=$ oleic acid (O), 18:2 = linoleic acid (L), and 18:3 = linolenic acid ( $\mathrm{Ln})$.

materials. Soybean oil, SO, presented an IV of 129 , with predominant unsaturated fatty acids, e.g., linoleic acid (56\%) and oleic acid (24\%). The partially hydrogenated SO (PH) presents an IV of 33.1. As reported in Table 1, partial hydrogenation of soybean oil produces the total loss of C18:3 (linolenic) and C18:2 (linoleic). As a consequence, the amount of C18:1 (oleic) increases from 24.0 to $39.4 \%$ and the amount of $\mathrm{C} 18: 0$ (stearic) increases from 4.5 to $49.5 \%$. Fully hydrogenated oil (FH) has an IV of 3.5 , and it is mainly composed, as expected, of stearic acid moieties (88\%), in agreement with that reported elsewhere. ${ }^{21,22}$ The IV of the blends are linear combinations of the original values of their constituents, 18.3 for $50 / 50$ and 9.4 for $80 / 20$, respectively.

The chemical interesterification (CI) process does not affect the degree of saturation or cause the isomerization of the double bonds of the fatty acids; therefore, alterations in the IV and the fatty acid compositions of the mixtures are not expected. ${ }^{23,24}$ Then, in order to investigate the effect of $\mathrm{CI}$, a comparison of the TAG profile in each sample was performed by GC.

Table 2 shows the triacylglycerol composition of raw materials $(\mathrm{PH}, \mathrm{FH})$ and the blends, before and after chemical

Table 2. Triacylglycerol Compositions of the Materials

\begin{tabular}{llllllc} 
TAG & FH & PH & $80 / 20$ & $50 / 50$ & $80 / 20$ CI & $50 / 50$ CI \\
PSP & 3.2 & 1.9 & 2.5 & 2.5 & $3.1 \uparrow$ & $3.1 \uparrow$ \\
POP & - & 1.1 & 0.3 & 0.9 & $0.3=$ & $0.7 \downarrow$ \\
PSS & 26.5 & 10.5 & 23.9 & 18.1 & $22.6 \downarrow$ & $16.6 \downarrow$ \\
POS & 1.3 & 10.3 & 3.7 & 6.3 & $4.4 \uparrow$ & $8.0 \uparrow$ \\
POO & - & 7.0 & 1.3 & 3.1 & $0.6 \downarrow$ & $2.5 \downarrow$ \\
SSS & 66.1 & 18.7 & 55.7 & 42.2 & $46.9 \downarrow$ & $34.9 \downarrow$ \\
SOS & 2.8 & 20.8 & 6.7 & 11.4 & $17.5 \uparrow$ & $23.6 \uparrow$ \\
SSO & - & - & - & - & $2.0 \uparrow$ & $2.0 \uparrow$ \\
SOO & - & 19.4 & 3.7 & 9.8 & $2.6 \downarrow$ & $6.7 \downarrow$ \\
OOO & - & 10.3 & 2.2 & 5.7 & n.d. & $2.0 \downarrow$ \\
\hline
\end{tabular}

interesterification (see SO TAG composition in Table S1). The main component of starting material FH is SSS with $66.1 \%$, followed by PSS with $26.5 \%$. In the case of the $\mathrm{PH}$ material, nine TAGs were quantified, where SOO, SOS, and SSS sum approximately $60 \%$, while OOO, POS, and PSS constitute the minor components with approximately $30 \%$ of the total TAGs. Then, the blends of the starting materials produce mixtures that are mainly composed by saturated TAGs, where the predominant species are SSS and PSS with $55.7 \%$ and $23.9 \%$ for sample $80 / 20$, and $42.2 \%$ and $18.1 \%$ for sample 50/50, respectively

As mentioned above, the interesterification reaction produces the exchange of fatty acid moieties in the TAG, changing the triacylglycerol profile and, therefore, the physical properties of the sample. ${ }^{25,26}$ This randomization resulted in the formation of the triacylglycerol SSO (not present in the original mixture), the increase of some TAG species, such as SOS, POS, and PPS, and the decrease of SSS, PSS, SOO, POO, and OOO. To facilitate the visualization, the relative increase/decrease of each TAG in the CI samples, as compared with the initial blends, is indicated with up and down arrows in Table 2.

In order to reduce the number of factors that represent the composition of each sample, a reduced group of variables were arranged according to their degree of saturation/unsaturation. Table 3 presents the triacylglycerol composition as follows: $S_{3}$

Table 3. TAG Composition by $\mathrm{S}_{3}, \mathrm{~S}_{2} \mathrm{U}, \mathrm{SU}_{2}$, and $\mathrm{U}_{3}$ Contents

\begin{tabular}{llccccc} 
TAG & FH & PH & $80 / 20$ & $50 / 50$ & $80 / 20 \mathrm{CI}$ & $50 / 50 \mathrm{CI}$ \\
$\mathrm{S}_{3}$ & 95.8 & 31.1 & 82.1 & 62.8 & $72.6 \downarrow$ & $54.5 \downarrow$ \\
$\mathrm{S}_{2} \mathrm{U}$ & 4.2 & 32.2 & 10.7 & 18.6 & $24.2 \uparrow$ & $34.3 \uparrow$ \\
$\mathrm{SU}_{2}$ & - & 26.4 & 5.0 & 12.9 & $3.2 \downarrow$ & $9.2 \downarrow$ \\
$\mathrm{U}_{3}$ & - & 10.3 & 2.2 & 5.7 & - & $2.0 \downarrow$ \\
\hline
\end{tabular}

(trisaturates), $\mathrm{S}_{2} \mathrm{U}$ (disaturates-monounsaturates), $\mathrm{SU}_{2}$ (monosaturates-diunsaturates), and $\mathrm{U}_{3}$ (triunsaturates). ${ }^{15}$ This representation will allows a simpler correlation between composition and physical properties of the samples.

$\mathrm{FH}$ possesses a high content in $\mathrm{S}_{3}(95.8 \%)$, while $\mathrm{PH}$ presents a more balanced distribution of $S_{3}, S_{2} U$, and SU2. For the blends, a large concentration of $S_{3}$ is observed: $82.1 \%$ for $80 / 20$ and $62.8 \%$ for $50 / 50$. As expected, after the CI reaction 

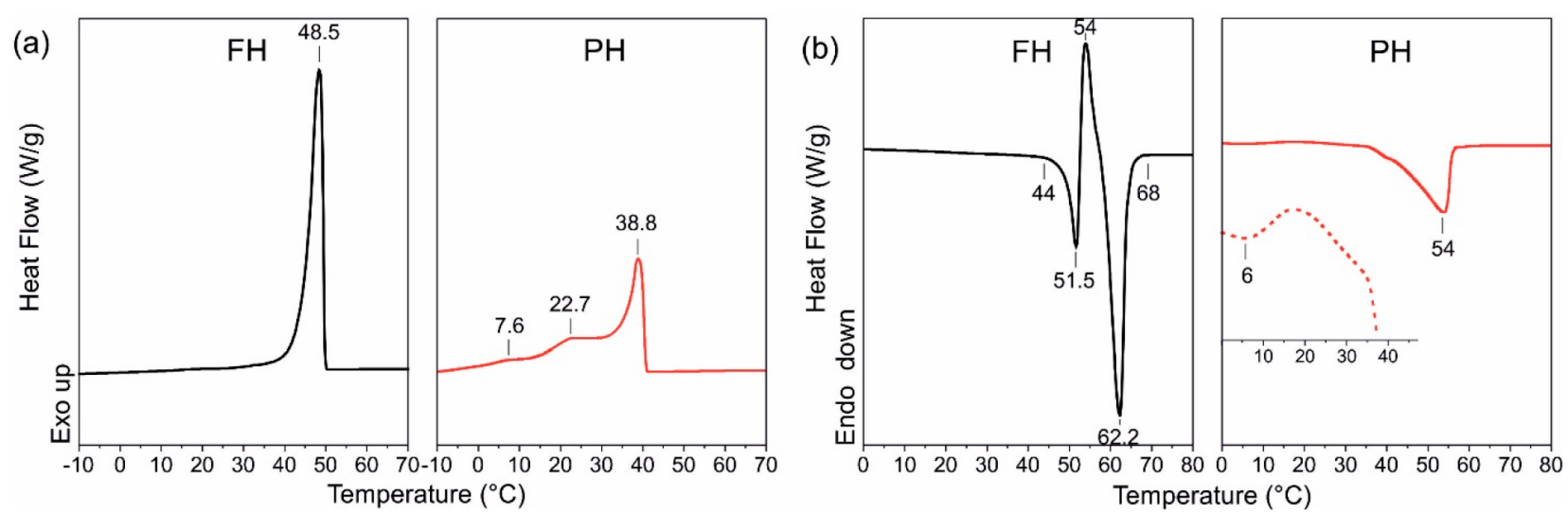

Figure 1. DSC (a) crystallization and (b) melting curves of $\mathrm{FH}$ and $\mathrm{PH}$ materials.
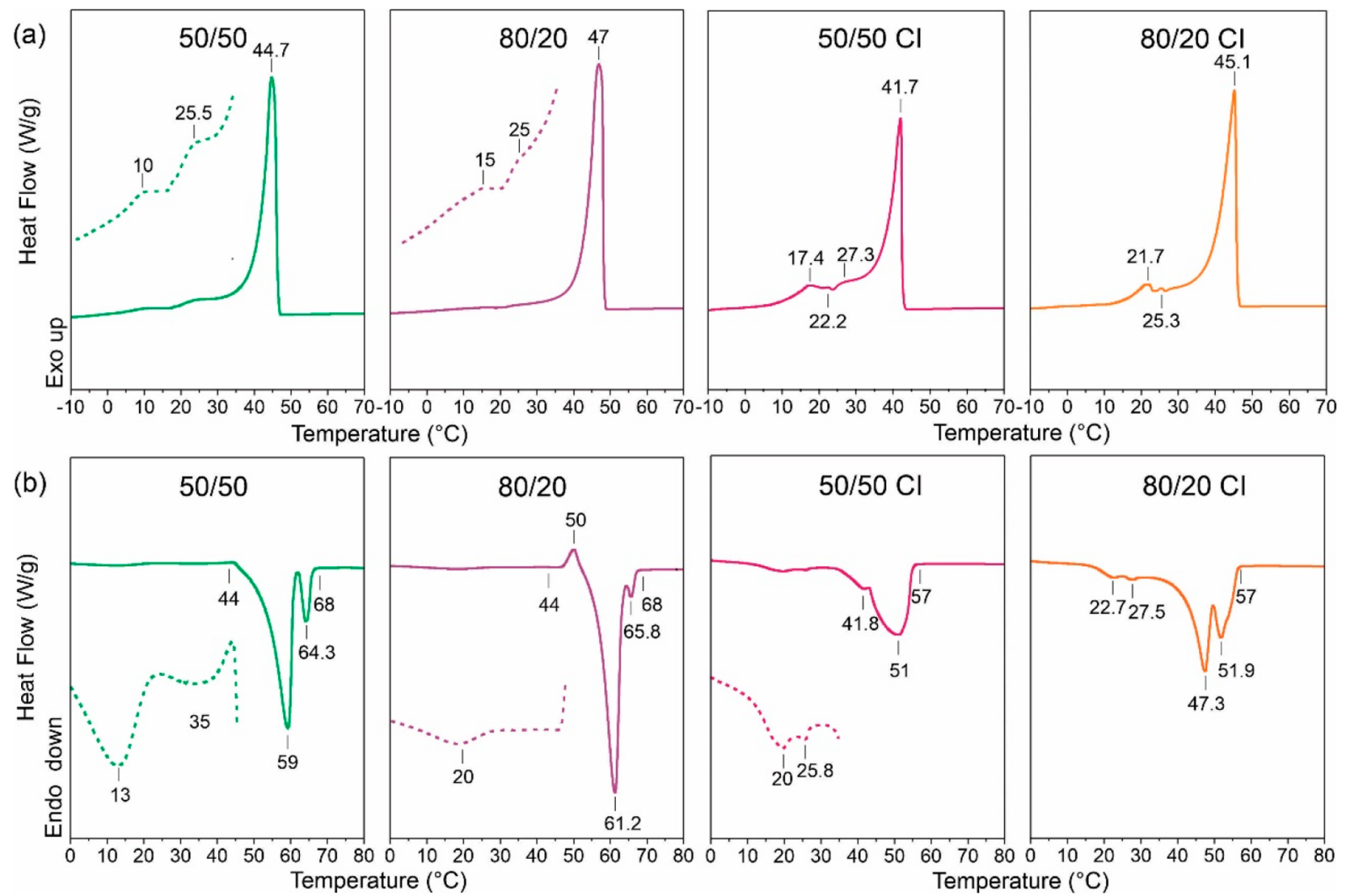

Figure 2. DSC (a) crystallization and (b) melting curves of blends before and after CI.

a decrease in $S_{3}$ and $U_{3}$ components with the concomitant increase in intermediate TAGs: $\mathrm{S}_{2} \mathrm{U}$ and $\mathrm{SU}_{2}$ are observed. ${ }^{15}$ The prepared blends have a low content of TAG $\mathrm{U}_{3}$, as a consequence of the hydrogenation process; therefore, after CI $\mathrm{S}_{3}, \mathrm{U}_{3}$, and $\mathrm{SU}_{2}$ decrease and only $\mathrm{S}_{2} \mathrm{U}$ increases.

3.2. Thermal Analysis. The thermal behavior of the prepared samples was exhaustively analyzed by DSC. While TAG crystallization produces a volume contraction associated with an exothermic transition, melting yields a volume expansion, characterized by an endothermic process. The thermal profiles of lipids could be complex due to their complex TAG compositions, as well as because of their polymorphism. $^{27-30}$ DSC from soybean oil (Figure S1) is an example of this complex behavior, which is widely investigated in the literature. ${ }^{31-33}$
Figure 1 shows DSC thermograms for the starting materials, where their crystallization (a) and melting (b) processes are observed during cooling and heating ramps, respectively. $\mathrm{FH}$ sample presents a crystallization profile that resembles the one of pure tristearine (SSS) with a peak of crystallization temperature at $48.5{ }^{\circ} \mathrm{C}$. ${ }^{34}$ Its single exothermic peak is associated with the composition of TAG, mainly $S_{3}$ (trisaturated).

The fusion curve (heating) of the $\mathrm{FH}$ sample has a melting range from 44 to $68{ }^{\circ} \mathrm{C}$; in general, the low temperature peak $\left(51.5{ }^{\circ} \mathrm{C}\right)$ is ascribed to the fusion of the $\alpha$ polymorph, transformed via recrystallizations (exothermic peak $54{ }^{\circ} \mathrm{C}$ ) into a more stable phase which fully melts at a higher temperature, close to $68{ }^{\circ} \mathrm{C}$ (peak temperature at $62.2{ }^{\circ} \mathrm{C}$ ). Although $\mathrm{FH}$ has almost $90 \%$ of stearic acid moieties, the fusion profile is 

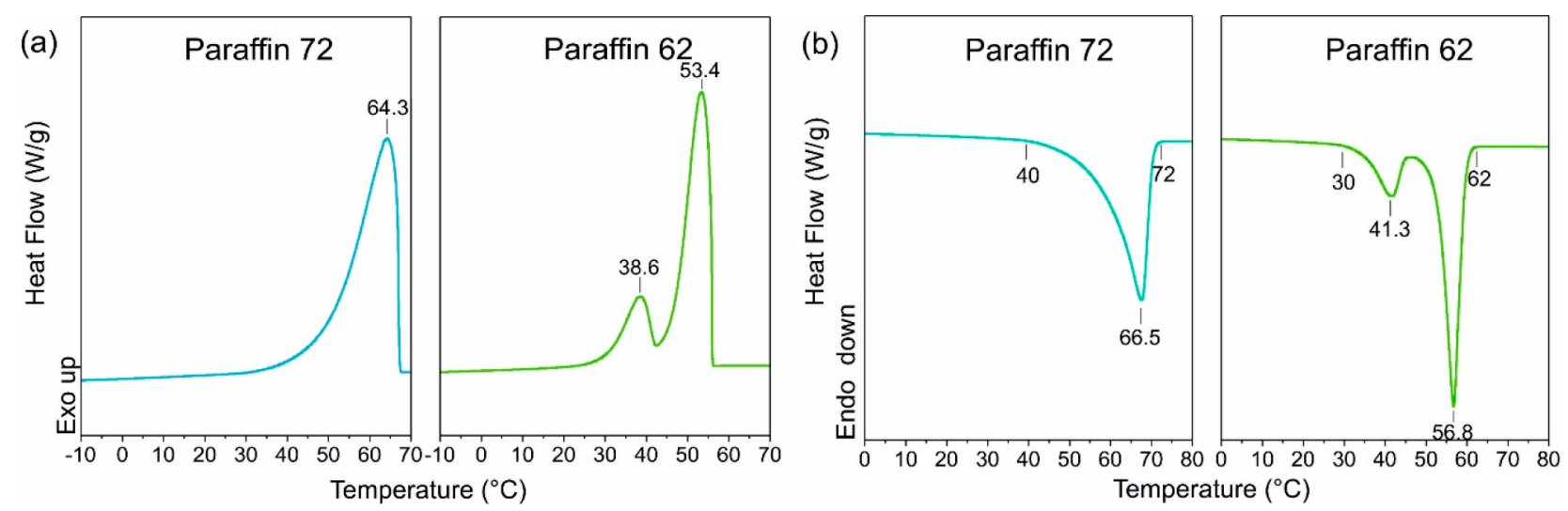

Figure 3. DSC (a) crystallization and (b) melting curves of paraffins.

different from the profile of pure SSS (nor is a linear combination of their pure components, e.g., SSS, PSS, $\left.\operatorname{PPS}^{34,35}\right)$. It is remarkable that the high temperature peak is downshifted from $72{ }^{\circ} \mathrm{C}$ (pure SSS) to $62.2{ }^{\circ} \mathrm{C}$ in the $\mathrm{FH}$ sample. Similarly, the low temperature peak also decreases from 55 to $51.5^{\circ} \mathrm{C}$. Bouzidi et al..$^{34,35}$ investigated the crystal structures and thermal behaviors of pure SSS, PSS, and PPS TAGs and of the binary mixture PSS/SSS, suggesting that PSS has a strong effect on the physical properties of the mixture due to the chain length mismatch (CLM) between the fatty acid chains. Clearly, the presence of PSS (26.5\%) considerably lowers the melting point in comparison with pure SSS. Similar results from fully hydrogenated soybean oil were reported by Adhikari et al. ${ }^{36}$

For PH sample, Figure 1a shows that the main peak crystallization is located at $38.8^{\circ} \mathrm{C}$. The well-defined peak can be associated with $S_{3}$ components, and the adjacent shoulders can be associated with intermediate and fully unsaturated triglycerides. In the melting profile, $\mathrm{PH}$ sample presents a broad endothermic peak at $54{ }^{\circ} \mathrm{C}$ (Figure 1b), which is ascribed to the presence of a high content of oleic and stearic acid moieties, 39.4 and $49.5 \%$, respectively, i.e., that are part of partially unsaturated TAGs $\left(32.2 \% \mathrm{~S}_{2} \mathrm{U}\right.$ and $\left.26.4 \% \mathrm{SU}_{2}\right)$ which presented intermediate melting points. Additionally, a very small peak is registered at $6{ }^{\circ} \mathrm{C}$ (observed in the zoom of the DSC thermogram inserted in Figure $1 \mathrm{~b}$ for the PH sample) due to the $10.3 \% \mathrm{U}_{3}$, triunsaturated, TAG.

Figure 2 shows the cooling and heating thermograms of the blend samples before and after CI. Before the CI reaction, increases in the peak crystallization temperature are observed when the $\mathrm{FH}$ content of blend is augmented, from $44.7^{\circ} \mathrm{C}$ for $50 / 50$ to $47^{\circ} \mathrm{C}$ for $80 / 20$. Both mixtures present peaks at low temperatures of about 10 and $25{ }^{\circ} \mathrm{C}$, due to the presence of unsaturated TAGs.

The heating profiles exhibit some features similar to those of the starting materials; however, it is important to note that the DSC profiles are not a mere linear combination thereof. In general, it can be observed that both blends present a melting range similar to that of FH sample, between 44 and $68{ }^{\circ} \mathrm{C}$. This behavior can be assigned to the high content of $\mathrm{S}_{3}$. The peaks at low temperatures are attributed to their TAGs composition that possess unsaturated fatty acids. The presence of unsaturated moieties generates an overall decrease of the consistency, as will be discussed below.

As mentioned above, fusion behaviors of polymorphs are highly determined by the intrinsic TAG compositions. Two types of transformation processes occur from less stable to more stable polymorphic forms: melting-mediated and solid state transformations. ${ }^{37}$ In the first case, a less thermostable polymorph reorganizes when melting and recrystallizes in a more stable polymorph, generating an exothermic peak (as pointed out for the FH sample). In the second case, the transformation can occur without previous melting events, ${ }^{27}$ highlighted by an exothermic peak as observed for the blend $80 / 20$ at $50{ }^{\circ} \mathrm{C}$.

DSC thermograms from CI blends present changes generated by the modification in the TAGs composition (Tables 2 and 3). The increase of $S_{2} \mathrm{U}$ can be verified by the appearance of new shoulders after the main peak in the crystallization curves. The main peak shows a slight reduction, to $41.7{ }^{\circ} \mathrm{C}$ for the $50 / 50 \mathrm{CI}$ and $45.1{ }^{\circ} \mathrm{C}$ for the $80 / 20 \mathrm{CI}$, mainly due to the decreased $\mathrm{S}_{3}$ content in both samples. For these same reasons, in the melting curve it is observed that the CI materials melted completely around $57^{\circ} \mathrm{C}$, that is, about 11 ${ }^{\circ} \mathrm{C}$ lower than the original blends. As expected, the interesterification produced a decrease in the melting point by the rearrangement of the TAG composition. ${ }^{16,38}$

For comparison proposes, Figure 3 presents the DSC profiles of two commercial paraffins widely used in industry. Paraffin 72 has a melting range between 40 and $72{ }^{\circ} \mathrm{C}$, characteristic of a microcrystalline wax. Microcrystalline waxes are mainly composed by $n$-alkanes between $\mathrm{C}_{33}$ and $\mathrm{C}_{60},{ }^{1}$, with a wide melting range in a single broad peak. In the case of lower molecular weight waxes $\mathrm{C}_{17}-\mathrm{C}_{34}$ (macrocrystalline waxes), ${ }^{1}$ in general, two characteristic peaks are observed: one sharper caused by melting and the other due to a solidsolid phase transition. ${ }^{39-41}$ As observed, paraffin 62 presents a melting range from 30 to $62{ }^{\circ} \mathrm{C}$. The final melting ranges of these mineral waxes are higher than those of the bio-paraffins prepared in this work. However, in addition to the melting point it is important to consider the texture and plasticity of these materials to determine wax uses. Thus, the degree of crystallinity has a major influence on the hardness, density, and transparency of the material, ${ }^{40}$ all of which govern the range of applications.

3.3. Polymorphism. X-ray analysis was used to characterize the crystal structures of the investigated materials. TAG molecules can crystallize into different crystalline polymorphs, which can exhibit significantly different melting points and textural properties. The basic polymorphs of lipids are $\alpha, \beta^{\prime}$, and $\beta$, where their chains are packed in hexagonal, orthorhombic, and triclinic structures, respectively. ${ }^{42}$ The $\alpha$ 
form shows a characteristic diffraction peak at $4.15 \AA$. The $\beta^{\prime}$ form is characterized by having two main diffraction peaks at 3.8 and $4.2 \AA$, while the $\beta$ form is associated with a series of diffraction peaks, one prominent at $4.6 \AA$ and others of less intensity at $3.6-3.9 \AA$. $^{10}$

Figure 4 shows the X-ray diffractograms from each synthesized material and for the mineral waxes. The XRD

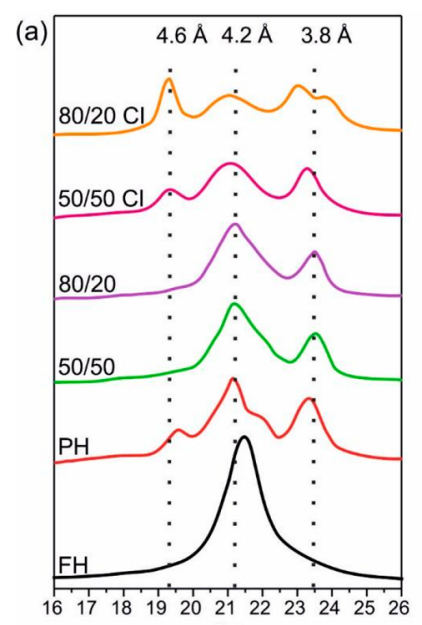

$2 \theta$

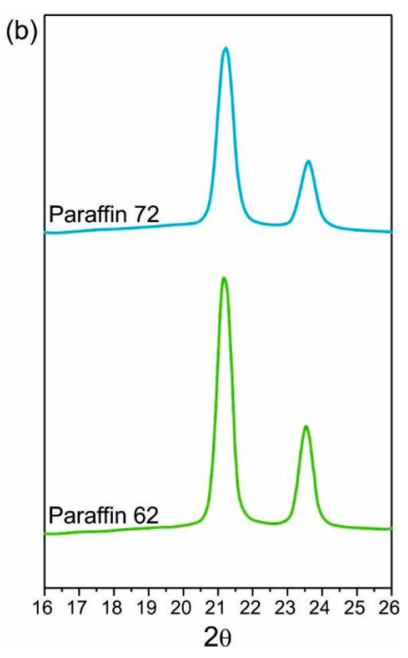

$2 \theta$
Figure 4. X-ray diffraction patterns of synthesized materials (a) and paraffins (b).

pattern of FH shows a peak at $4.15 \AA$ corresponding to the $\alpha$ polymorph as a result of a rapid cooling process, in agreement with previous reports. ${ }^{36} \mathrm{PH}$ sample shows the characteristic peaks of the $\beta^{\prime}$ form; in addition it presents two peaks at approximately 4.5 and $4.0 \AA$ that are usually associated with a pseudo- $\beta^{\prime}$ form. ${ }^{42-44}$

The binary blends $80 / 20$ and $50 / 50$ present $\beta^{\prime}$ crystals characterized by peaks at 4.2 and $3.8 \AA$ and some possible contributions of $\alpha$ polymorph around $4.1 \AA$. This last contribution could be due to the combination of mixed TAGs with high content of $\mathrm{S}_{3}$ TAG. ${ }^{38}$ Possibly the high proportion of SSS in the samples produces a faster crystallization and therefore a rapid increase in viscosity that limits heat and mass transfer. This makes molecular arrangement difficult ${ }^{21}$ and thus leads to other triacylglycerols crystallizing in the polymorph $\beta^{\prime}$, which is less stable form but more kinetically accessible under these conditions. ${ }^{45}$ After chemical interesterification, the materials present both forms $\left(\beta^{\prime}\right.$ and $\left.\beta\right)$. The relative intensities of the peaks at 4.2 and $4.6 \AA$ show that the $\beta^{\prime}$ form prevails in the $50 / 50 \mathrm{CI}$ sample while the $\beta$ polymorph is higher in $80 / 20 \mathrm{CI}$. It is well-known that small changes in the composition of TAG can vary the polymorphic form in which the fat crystallizes. As shown before, $C I$ increases the amount of $S_{2} U$ components and decreases $\mathrm{S}_{3}$ TAG (Tables 2 and 3); as a consequence it can be speculated that the decrease in the viscosity of the system allows the samples to crystallize in the most stable polymorph. ${ }^{46,47}$

On the other hand, commercial mineral waxes (Figure $4 \mathrm{~b}$ ) presented the typical orthorhombic structure $\left(\beta^{\prime}\right)$, which is characteristic of mixtures of $n$-alkanes or $n$-alkanes with other types of hydrocarbons. ${ }^{48,49}$

3.4. Microstructure. The concept of microstructure includes information on the state, quantity, shape, size, spatial relationships, and interaction between all the components of the crystal lattice; therefore, it greatly influences the macroscopic properties of materials. The shape and size of the crystalline particles depend on several factors, with the most important being the crystallization conditions (cooling rate, initial and final temperatures, stirring speed) and composition (fatty acid profile and TAG composition for plant derivatives and relationship between linear, branched, and cyclic hydrocarbons for mineral derivatives). The microstructural level (or mesoscale) of a fatty crystal network can be defined as structures with dimensions between approximately 1 and 200 $\mu \mathrm{m} .{ }^{50}$ The growth of this crystal network begins when the TAG molecules presented in the sample organize and crystallize from the melt, through a continuous aggregation process, ${ }^{51}$ forming needle-shaped crystals and/or spherulites with average final sizes of 5 and $20 \mu \mathrm{m}$, respectively. Additionally, spherulite particles often tend to aggregate $(100-200 \mu \mathrm{m})$. $^{50}$

Polarized light microscopy was used to visualize the microstructural network of the investigated samples. ${ }^{37}$ Figure
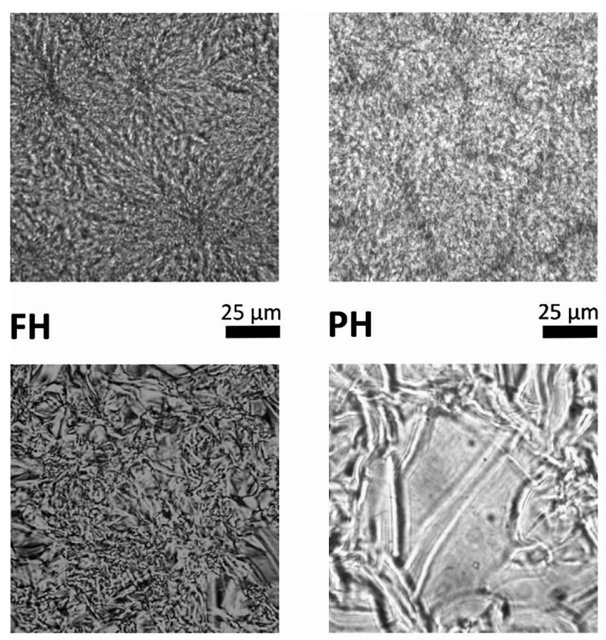

Paraffin $72 \quad 25 \mu \mathrm{m}$

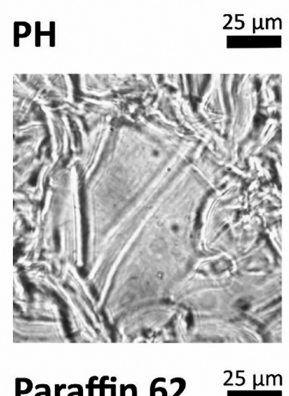

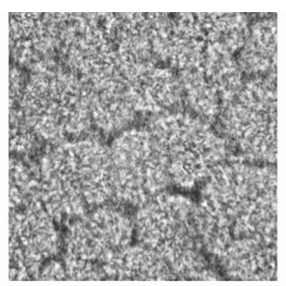

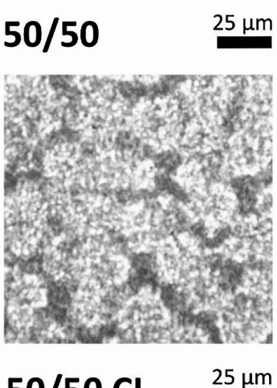

$50 / 50 \mathrm{Cl} \quad 25 \mu \mathrm{m}$
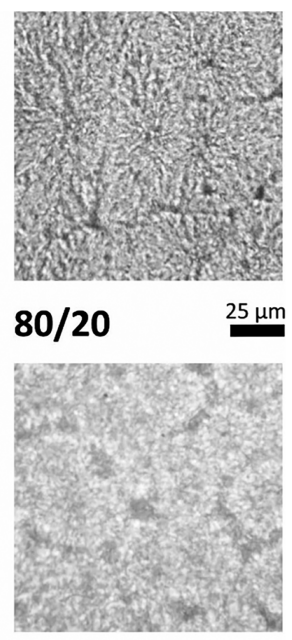

$80 / 20 \mathrm{Cl} \quad 25 \mu \mathrm{m}$

Figure 5. PLM of raw materials, mixtures before and after CI, and commercial paraffins. 


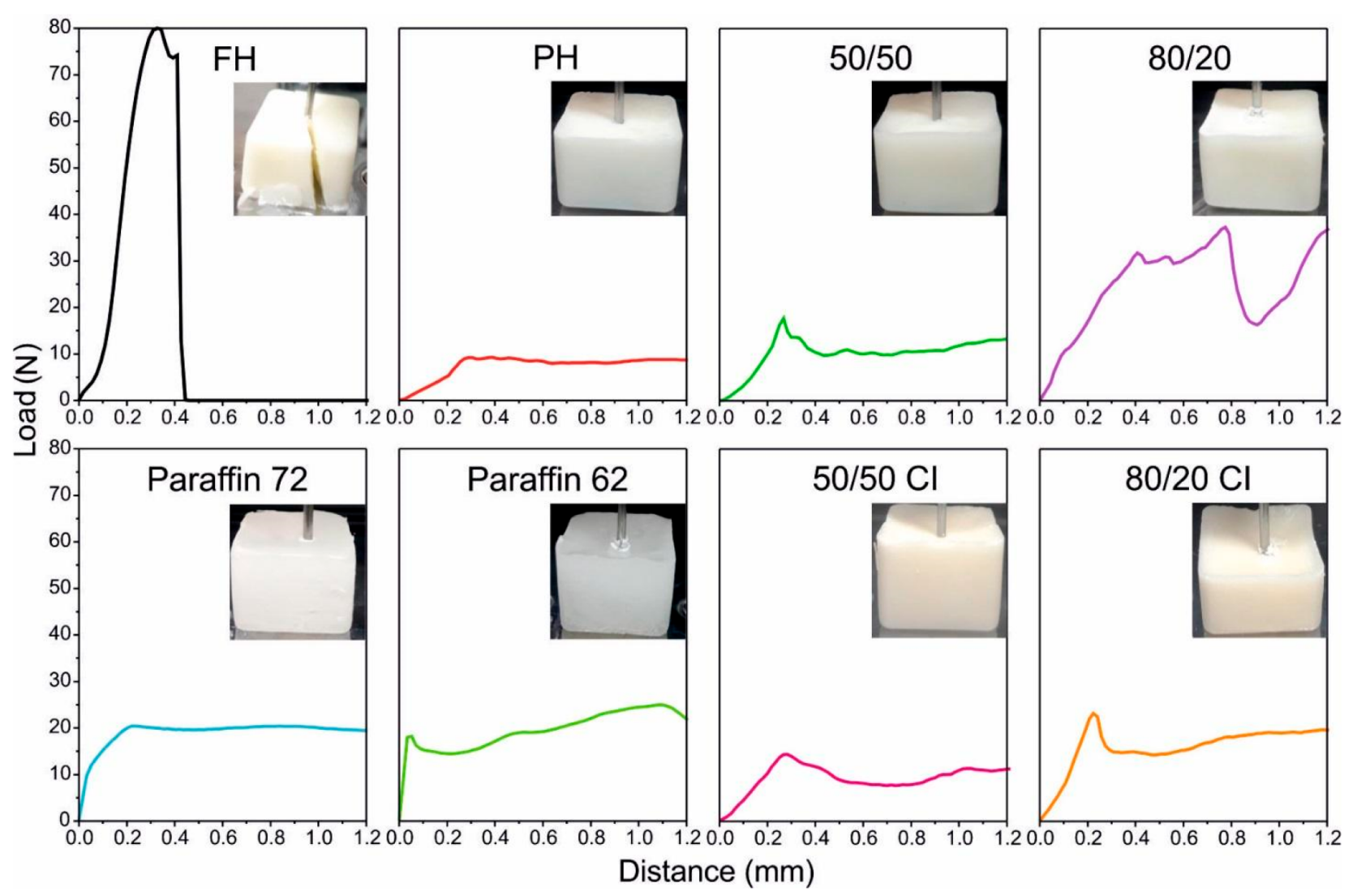

Figure 6. Textural profiles obtained during penetration test. The photographs of penetrated samples at the end of the assays are inserted in each corresponding plot.

5 shows the crystal morphology of all investigated samples at $25{ }^{\circ} \mathrm{C}$. According to Shi et al., ${ }^{52}$ crystal morphology in a mixture is dominated by the TAG species with the highest melting point. The differences between the microstructures can be attributed to the different content of $S_{3}$ in each sample (see Table 3). The modification in the aggregation of fat crystals cannot be readily explained by the polymorphic crystal structure, ${ }^{53}$ since a single crystal polymorph can exhibit multiple morphologies. ${ }^{47}$

The samples with the highest content of $\mathrm{S}_{3}, \mathrm{FH}$ and 80/20, present large crystals and a compact lattice density; ${ }^{47}$ the contours of the spherulite aggregates are barely distinguishable. These structures frequently form hard and fragile materials, ${ }^{2}$ as will be discussed later. On the other hand, the samples that contain higher amounts of unsaturated fatty acids, $\mathrm{PH}$ and 50/ 50 , formed poorly defined aggregates with voids (dark contrast lines in the images). The presence of voids results from the contraction of the solid phase during crystallization to a more stable polymorphic form. ${ }^{54}$

Interesterification reaction produces important changes in the crystal sizes, as compared with the original mixtures, but not in the overall morphology. Both interesterificated samples, 50/50 CI and 80/20 CI, present smaller spherulite crystals (about 25 and $65 \mu \mathrm{m}$ respectively), generating a greater space between them, voids, which could influence the hardness and plasticity of the material.

Mineral paraffins are generally classified as plaques, needles, and so-called malformations. ${ }^{55}$ Rapid cooling generally creates many imperfections: bent and twisted plates, needles, and other imperfections. ${ }^{48}$ It is generally accepted that constituents with higher melting points crystallize in plates, while components with low melting points crystallize in needles. Paraffin 72 has observed platelike crystals, with well-defined borders about $25 \mu \mathrm{m}$, and malformations, while paraffin 62 also presents needlelike crystals and a less compact structure. This microstructure is related to the cohesiveness shown by both commercial samples (section 3.5).

3.5. Texture. The polymorphism, size distribution, and shape of the TAG crystals, as well as, the network formed between the crystals, play a key role in determining the textural characteristics of lipid-based materials. The nature and intensity of bonding forces in the microstructure determine the material's brittleness and cohesiveness. ${ }^{10}$ Penetration testing was used to investigate the texture profiles of the samples. Figure 6 shows the load-distance curve obtained from the penetration test. Inserted pictures in Figure 6 show the corresponding images of the penetrated sample at the end of the assay. The first slope of the textural profile indicates the resistance of the material to be penetrated, arriving at the maximum value of load, which represents the hardness (and the firmness) of a material. Figure S2 compares the maxima of texture profiles with those obtained with a Shore durometer type A. It is observed that both values present an equivalent variation among the samples, evidencing that the maximum value of the texture profile is directly related to the material hardness. Once the sample is penetrated, the shape of the textural curve is a consequence of cohesion and brittleness features of the sample. Yao et al. ${ }^{49}$ states that the shape of a negative slope (after its maximum) and the ratio between the valley and peak values (VTP) of the texture profile provided 
good information on the material's cohesiveness and brittleness. A curve with a constant penetration load after its maximum shows a homogeneous resistance throughout the test, indicating a highly cohesive material. On the other extreme, a low VTP with a sharp maximum and noticeable slope evidences a low cohesive material, where the penetration/compression resistance is different in its surface than in its bulk.

The commercial mineral paraffins selected as reference materials present a good example of cohesion, where they undergo a practically stable plastic deformation with their maximum load conserved throughout the textural test. This mechanical feature of commercial mineral waxes 72 and 62, their melting range, and their brightness are some of the desired properties for industrial applications of this kind of material. Both samples present a high degree of refinement and a slightly white to transparent hue. ${ }^{1}$ Specifically, the penetration curve of paraffin 72 shows an increase up to 20 $\mathrm{N}$ at $0.2 \mathrm{~mm}$, followed by a smooth and almost constant load through the test. In turn, paraffin 62 shows a very sharp increase in the loading, up to a peak at $20 \mathrm{~N}(0.05 \mathrm{~mm})$, followed by a valley and slight increase in the applied force through the test. These curves are characteristic of a homogeneous and cohesive material. The small variation observed in the curves may be due to the difference in crystalline structures as observed in PLM.

The synthesized materials investigated in this work will be compared with the penetration profiles of mineral waxes, as an objective function, to obtain bio-paraffins with a possible technological value. FH sample presents the highest hardness, with a peak value of $80 \mathrm{~N}$ at $0.3 \mathrm{~mm}$, followed by a decrease to zero load indicative of the formation of a crack in the sample (see inserted picture in Figure 6). The absence of a valley indicates a low capability of flowing under compression; i.e., no plastic deformation is observed which corresponds to a brittle material. This behavior is related to the very high content of trisaturate TAG $\left(\mathrm{S}_{3}\right)$, with its fast crystallization into $\alpha$ polymorph, producing a network of highly compact spherulite aggregates, which restrict the material capability of deforming. ${ }^{47}$

Very interestingly, the $\mathrm{PH}$ sample presents a gradual increase of loading up to approximately $10 \mathrm{~N}$ at $0.3 \mathrm{~mm}$, followed by an almost constant load through the test. This behavior is characteristic of a soft solid material. It is worth noticing that this sample presents a smooth surface, without greasiness in spite of its high content of unsaturated fatty acids. The $\mathrm{PH}$ microstructure shows large spherulites that could retain the oil; i.e., the oil is enclosed in the network.

The 50/50 sample shows a loading peak $(18 \mathrm{~N})$ at $0.26 \mathrm{~mm}$ and then falls and remains almost constant around $15 \mathrm{~N}$. The low VTP value and its sharp trasition from peak to valley evidence some lack of cohesion. The blend possess an increased hardness to compare with the $\mathrm{PH}$ material, ascribed to the increased content of saturated TAG in the 50/50 material (see Table 3). In turn, this is in agreement with the higher separation between spherulite aggregates, that is, low connection between microcrystals as shown in the PLM image. ${ }^{47}$ However, small oscillations can be observed from the peak, which can be ascribed to some instability during the compression assays and/or microcracking formation along the material.

As mentioned above, one of the effects of the CI is the decrease of the $S_{3}$ content while increasing the $S_{2} U$ TAG.
Although the 50/50 CI sample conserves a qualitatively similar penetration curve of its original blend, some performance improvements are observed. This material presents a peak value of $14.6 \mathrm{~N}$ at $0.27 \mathrm{~mm}$, followed by a smoother and less pronounced slope, indicating cohesiveness improvement. Also, the observed instability registered in the original 50/50 mixture is no longer noticed in that of CI sample, indicating an enhancement in the penetration resistance. The microstructure showed a higher space between the spherulite aggregates (voids) as compared with the original 50/50 sample (Figure 5). However, this material presents a good oil-binding capacity; i.e., oil loss is not observed, as can be appreciated in the inserted picture (Figure 6).

In the $80 / 20$ blend, an almost linear increase of the applied force is observed up to $0.4 \mathrm{~mm}(30 \mathrm{~N}$; this value is the highest among the mixtures due to its high $S_{3}$ content). Then, some substantial oscillations are observed, which indicate some microcracking or possibly the presence of grains with different hardness. Finally, after $0.8 \mathrm{~mm}$ of penetration is reached, a sharp load decrease is registered with a new linear increase. This behavior may be related to the formation of shavings (visually observed), which could be associated with a hard material and the formation of microcracks inside the sample (i.e., low plastic deformation capability). The PLM image showed the presence of large crystals and a compact network.

In the case of the $80 / 20 \mathrm{CI}$ sample, a remarkable change in the penetration curve is observed as compared with the original mixture. The initial increase of the loading reached a peak at $0.22 \mathrm{~mm}$ (approximately $22 \mathrm{~N}$ ). The reduction of TAG of high melting temperature decreased the bio-paraffin hardness. After the peak, the curve looks smooth and without instabilities; i.e., cohesiveness is improved. The penetration curve displayed by $80 / 20 \mathrm{CI}$ sample presents the typical shape of a highly cohesive material with a significant plastic deformation when it reaches a load of around $20 \mathrm{~N}$. This response is related to the microstructure, where large spherulites but with a less compact network than the original blend was observed (Figure 5). XRD analysis showed that the $\beta$ polymorph dominates in this material. However, the characteristic grainy texture of this polymorph ${ }^{47}$ is not observed (see inserted picture in Figure 6). This could be due to the presence of $\beta^{\prime}$ polymorph, which could hamper the growth of $\beta$ crystals. Nevertheless, this is not clear at this point.

In summary, it can be concluded that the chemical interesterification reaction improves the texture and rheological behavior of the investigated samples. The penetration test curves of the CI mixtures are comparable with the curves of the commercial paraffins; the hardness values as well the cohesiveness are close. The synthesized materials present thermal behaviors in the range of many industrial applications, which makes them good candidates as replacements for mineral paraffin.

\section{CONCLUSIONS}

This study shows a simple process to produce bio-paraffins, using only soybean oil as raw substance, with wanted thermal and textural properties for industrial applications with potential for mineral wax substitution. Totally and partially (IV 33.1) hydrogenated soybean oils were blended at two levels and subsequently chemically interesterified (CI) with sodium methoxide. The resulting materials were characterized and compared with two commercial mineral waxes. 
The chemical composition determined by gas chromatography showed that CI significantly modified the distribution of triacylglycerols, decreasing trisaturated and increasing monounsaturated TAGs. This modification alters the thermal behavior as shown by differential scanning calorimetry. An overall decrease of the crystallization and melting profile was observed after CI. In turn, the polymorph crystallization and microstructure are also affected by the interesterification process; $\beta$ and $\beta^{\prime}$ crystals and small spherulites are observed by X-ray diffraction and polarized light microscopy, respectively.

Finally, the textural performances of the synthesized materials are compared with the two commercial mineral waxes by the penetration test. CI produces substantial improvement of the loading curves as compared with those of the initial materials and blends. Particularly, both CI blends improve in hardness, cohesiveness, and plasticity. Moreover, they show loading curves comparable to the commercial waxes with useful temperature melting ranges. Therefore, the vegetable oil based bio-paraffins have shown great potential as a sustainable replacement for mineral waxes in industrial applications.

\section{ASSOCIATED CONTENT}

\section{S1 Supporting Information}

The Supporting Information is available free of charge at https://pubs.acs.org/doi/10.1021/acs.iecr.1c00322.

TAG composition and thermal behavior (DSC) of the neat soybean oil used; comparison of hardness values of materials (PDF)

\section{AUTHOR INFORMATION}

\section{Corresponding Author}

Sebastián E. Collins - Instituto de Desarrollo Tecnológico para la Industria Química, CONICET-UNL, 3000 Santa Fe, Argentina; Facultad de Ingeniería Química, Universidad Nacional del Litoral (UNL), 3000 Santa Fe, Argentina; (1) orcid.org/0000-0002-2157-3305; Phone: +54(342) 4559175; Email: scollins@santafe-conicet.gov.ar

\section{Authors}

Sandra Romero - Instituto de Desarrollo Tecnológico para la Industria Química, CONICET-UNL, 3000 Santa Fe, Argentina

Roque J. Minari - Instituto de Desarrollo Tecnológico para la Industria Química, CONICET-UNL, 3000 Santa Fe, Argentina; Facultad de Ingeniería Química, Universidad Nacional del Litoral (UNL), 3000 Santa Fe, Argentina; (1) orcid.org/0000-0003-3645-5317

Complete contact information is available at:

https://pubs.acs.org/10.1021/acs.iecr.1c00322

\section{Notes}

The authors declare no competing financial interest.

\section{ACKNOWLEDGMENTS}

This work was supported by the National Council for Scientific and Technical Research-CONICET [PUE 007].

\section{REFERENCES}

(1) Krendlinger, E.; Wolfmeier, U.; Schmidt, H.; Heinrichs, F.-L.; Michalczyk, G.; Payer, W.; Dietsche, W.; Boehlke, K.; Hohner, G.;
Wildgruber, J. Waxes. In Ullmann's Encyclopedia of Industrial Chemistry; Wiley-VCH Verlag GmbH \& Co. KGaA: Weinheim, Germany, 2015; pp 1-63.

(2) Fei, T.; Walker, J. A.; Vickerman, K. L.; Stanley, L. M.; Jarboe, D.; Wang, T. Synthesis and Characterization of Soybean Oil-Based Waxes and Their Application as Paraffin Substitute for Corrugated Coating. J. Ind. Eng. Chem. 2018, 58, 113-122.

(3) Palou, A.; Cruz, J.; Blanco, M.; Larraz, R.; Frontela, J.; Bengoechea, C. M.; González, J. M.; Alcalà, M. Characterization of the Composition of Paraffin Waxes on Industrial Applications. Energy Fuels 2014, 28 (2), 956-963.

(4) Miao, S.; Wang, P.; Su, Z.; Zhang, S. Vegetable-Oil-Based Polymers as Future Polymeric Biomaterials. Acta Biomater. 2014, 10 (4), 1692-1704.

(5) De, S.; Malik, S.; Ghosh, A.; Saha, R.; Saha, B. A Review on Natural Surfactants. RSC Adv. 2015, 5 (81), 65757-65767.

(6) Gorla, G.; Kour, S. M.; Padmaja, K. V.; Karuna, M. S. L.; Prasad, R. B. N. Preparation and Properties of Lubricant Base Stocks from Epoxidized Karanja Oil and Its Alkyl Esters. Ind. Eng. Chem. Res. 2013, 52 (47), 16598-16605.

(7) Alagi, P.; Ghorpade, R.; Jang, J. H.; Patil, C.; Jirimali, H.; Gite, V.; Hong, S. C. Functional Soybean Oil-Based Polyols as Sustainable Feedstocks for Polyurethane Coatings. Ind. Crops Prod. 2018, 113, 249-258.

(8) Luo, Q.; Liu, M.; Xu, Y.; Ionescu, M.; Petrović, Z. S. Thermosetting Allyl Resins Derived from Soybean Oil. Macromolecules 2011, 44 (18), 7149-7157.

(9) Huang, X.; Yang, X.; Liu, H.; Shang, S.; Cai, Z.; Wu, K. BioBased Thermosetting Epoxy Foams from Epoxidized Soybean Oil and Rosin with Enhanced Properties. Ind. Crops Prod. 2019, 139 (16), 111540.

(10) Bailey, A. E.; Fereidoon, S. Bailey's Industrial Oil and Fat Products, 6th ed.; John Wiley \& Sons: Hoboken, NJ, 2005.

(11) Erickson, D. R. Practical Handbook of Soybean Processing and Utilization; AOCS Press and the United Soybean Board: Urbana, IL, 1995.

(12) Wang, L.; Wang, T. Chemical Modification of Partially Hydrogenated Vegetable Oil to Improve Its Functional Properties for Candles. J. Am. Oil Chem. Soc. 2007, 84 (12), 1149-1159.

(13) Yao, L.; Lio, J.; Wang, T.; Jarboe, D. H. Synthesis and Characterization of Acetylated and Stearylyzed Soy Wax. J. Am. Oil Chem. Soc. 2013, 90 (7), 1063-1071.

(14) Masuchi, M. H.; Gandra, K. M.; Marangoni, A. L.; de Sá Perenha, C.; Chiu, M. C.; Grimaldi, R.; Gonçalves, L. A. G. Fats from Chemically Interesterified High-Oleic Sunflower Oil and Fully Hydrogenated Palm Oil. J. Am. Oil Chem. Soc. 2014, 91 (5), 859-866.

(15) Ribeiro, A. P. B.; Grimaldi, R.; Gioielli, L. A.; Gonçalves, L. A. G. Zero Trans Fats from Soybean Oil and Fully Hydrogenated Soybean Oil: Physico-Chemical Properties and Food Applications. Food Res. Int. 2009, 42 (3), 401-410.

(16) Farmani, J.; Safari, M.; Hamedi, M. Trans-Free Fats through Interesterification of Canola Oil/Palm Olein or Fully Hydrogenated Soybean Oil Blends. Eur. J. Lipid Sci. Technol. 2009, 111 (12), 12121220.

(17) Naeli, M. H.; Farmani, J.; Zargaraan, A. Rheological and Physicochemical Modification of Trans-Free Blends of Palm Stearin and Soybean Oil by Chemical Interesterification. J. Food Process Eng. 2017, 40 (2), No. e12409.

(18) Grau, R. J.; Cassano, A. E.; Baltanas, M. Catalysts and Network Modeling in Vegetable Oil Hydrogenation Processes. Catal. Rev.: Sci. Eng. 1988, 30 (1), 1-48.

(19) Firestone, D. Official Methods and Recommended Practices of the AOCS, 6th ed.; AOCS Press: Urbana, IL, 2009.

(20) Pacheco, C.; Palla, C. A.; Crapiste, G. H.; Carrin, M. E. Simultaneous Quantitation of FFA, MAG, DAG, and TAG in Enzymatically Modified Vegetable Oils and Fats. Food Anal. Methods 2014, 7 (10), 2013-2022.

(21) Ribeiro, A. P. B.; Grimaldi, R.; Gioielli, L. A.; Dos Santos, A. O.; Cardoso, L. P.; Gonçalves, L. A. G. Thermal Behavior, 
Microstructure, Polymorphism, and Crystallization Properties of Zero Trans Fats from Soybean Oil and Fully Hydrogenated Soybean Oil. Food Biophys. 2009, 4 (2), 106-118.

(22) List, G. R.; Jackson, M.; Eller, F.; Adlof, R. O. Low Trans Spread and Shortening Oils via Hydrogenation of Soybean Oil. J. Am. Oil Chem. Soc. 2007, 84 (6), 609-612.

(23) Balakos, M. W.; Hernandez, E. E. Catalyst Characteristics and Performance in Edible Oil Hydrogenation. Catal. Today 1997, 35 (4), $415-425$.

(24) Karabulut, I.; Turan, S.; Ergin, G. Effects of Chemical Interesterification on Solid Fat Content and Slip Melting Point of Fat/Oil Blends. Eur. Food Res. Technol. 2004, 218 (3), 224-229.

(25) Marangoni, A. G.; Rousseau, D. Engineering Triacylglycerols: The Role of Interesterification. Trends Food Sci. Technol. 1995, 6 (10), 329-335.

(26) Marangoni, A. G.; Rousseau, D. The Influence of Chemical Interesterification on Physicochemical Properties of Complex Fat Systems: Melting and Crystallization. J. Am. Oil Chem. Soc. 1998, 75 (10), 1265-1271.

(27) Chiavaro, E. Differential Scanning Calorimetry: Applications in Fat and Oil Technology; CRC Press: Boca Raton, FL, 2014; pp 1-272.

(28) Cebula, D. J.; Smith, K. W. Differential Scanning Calorimetry of Confectionery Fats. Pure Triglycerides: Effects of Cooling and Heating Rate Variation. J. Am. Oil Chem. Soc. 1991, 68 (8), 591-595.

(29) Szydłowska-Czerniak, A.; Karlovits, G.; Lach, M.; Szłyk, E. XRay Diffraction and Differential Scanning Calorimetry Studies of B $\rightarrow \beta$ Transitions in Fat Mixtures. Food Chem. 2005, 92 (1), 133-141.

(30) Vereecken, J.; De Graef, V.; Smith, K. W.; Wouters, J.; Dewettinck, K. Effect of TAG Composition on the Crystallization Behaviour of Model Fat Blends with the Same Saturated Fat Content. Food Res. Int. 2010, 43, 2057-2067.

(31) Tan, C. P.; Man, Y. B. C. Comparative Differential Scanning Calorimetric Analysis of Vegetable Oils: I. Effects of Heating Rate Variation. Phytochem. Anal. 2002, 13 (3), 129-141.

(32) Tan, C. P.; Che Man, Y. B. Differential Scanning Calorimetric Analysis of Edible Oils: Comparison of Thermal Properties and Chemical Composition. J. Am. Oil Chem. Soc. 2000, 77 (2), 143-155.

(33) Zhang, N.; Yang, X.; Fu, J.; Chen, Q.; Song, Z.; Wang, Y. Production of Diacylglycerol-Enriched Oil by Glycerolysis of Soybean Oil Using a Bubble Column Reactor in a Solvent-Free System. J. Oleo Sci. 2016, 65 (3), 207-216.

(34) Bouzidi, L.; Narine, S. S. Relationships between Molecular Structure and Kinetic and Thermodynamic Controls in Lipid Systems. Part II: Phase Behavior and Transformation Paths of SSS, PSS and PPS Saturated Triacylglycerols - Effect of Chain Length Mismatch. Chem. Phys. Lipids 2012, 165 (1), 77-88.

(35) Bouzidi, L.; Narine, S. S. Relationships between Molecular Structure and Kinetic and Thermodynamic Controls in Lipid Systems: Part III. Crystallization and Phase Behavior of 1-Palmitoyl2,3-Stearoyl-Sn-Glycerol (PSS) and Tristearoylglycerol (SSS) Binary System. Chem. Phys. Lipids 2012, 165 (1), 105-119.

(36) Adhikari, P.; Shin, J. A.; Lee, J. H.; Kim, H. R.; Kim, I. H.; Hong, S. T.; Lee, K. T. Crystallization, Physicochemical Properties, and Oxidative Stability of the Interesterified Hard Fat from Rice Bran Oil, Fully Hydrogenated Soybean Oil, and Coconut Oil through Lipase-Catalyzed Reaction. Food Bioprocess Technol. 2012, 5 (6), 2474-2487.

(37) Sato, K.; Bayés-García, L.; Calvet, T.; Cuevas-Diarte, M. À.; Ueno, S. External Factors Affecting Polymorphic Crystallization of Lipids. Eur. J. Lipid Sci. Technol. 2013, 115 (11), 1224-1238.

(38) Zhang, L.; Muramoto, H.; Ueno, S.; Sato, K. Crystallization of Fully Hydrogenated and Interesterified Fat and Vegetable Oil. J. Oleo Sci. 2011, 60 (6), 287-292.

(39) Luyt, A. S.; Krupa, I. Thermal Behaviour of Low and High Molecular Weight Paraffin Waxes Used for Designing Phase Change Materials. Thermochim. Acta 2008, 467 (1-2), 117-120.

(40) Srivastava, S. P.; Agrawal, K. M.; Handoo, J.; Joshi, G. C. Phasetransition studies in n-alkanes and petroleum-related waxes - a review. J. Phys. Chem. Solids 1993, 54 (6), 639-670.
(41) Akishino, J. K.; Cerqueira, D. P.; Silva, G. C.; Swinka-Filho, V.; Munaro, M. Morphological and Thermal Evaluation of Blends of Polyethylene Wax and Paraffin. Thermochim. Acta 2016, 626, 9-12.

(42) Himawan, C.; Starov, V. M.; Stapley, A. G. F. Thermodynamic and Kinetic Aspects of Fat Crystallization. Adv. Colloid Interface Sci. 2006, 122, 3-33.

(43) D’Souza, V.; deMan, J. M.; deMan, L. Short Spacings and Polymorphic Forms of Natural and Commercial Solid Fats: A Review. J. Am. Oil Chem. Soc. 1990, 67 (11), 835-843.

(44) Lee, J. H.; Akoh, C. C.; Himmelsbach, D. S.; Lee, K. T. Preparation of Interesterified Plastic Fats from Fats and Oils Free of Trans Fatty Acid. J. Agric. Food Chem. 2008, 56 (11), 4039-4046.

(45) Acevedo, N. C.; Marangoni, A. G. Functionalization of NonInteresterified Mixtures of Fully Hydrogenated Fats Using Shear Processing. Food Bioprocess Technol. 2014, 7 (2), 575-587.

(46) Timms, R. Phase Behaviour of Fats and Their Mixtures. Prog. Lipid Res. 1984, 23, 1-38.

(47) Rousseau, D.; Marangoni, A. G.; Jeffrey, K. R. The Influence of Chemical Interesterification on the Physicochemical Properties of Complex Fat Systems: Morphology and Polymorphism. J. Am. Oil Chem. Soc. 1998, 75 (12), 1833-1839.

(48) Turner, W. R.; Turner, R. Normal Alkanes. Ind. Eng. Chem. Prod. Res. Dev. 1971, 10 (3), 238-260.

(49) Yao, L.; Wang, T. Textural and Physical Properties of Biorenewable "Waxes" Containing Partial Acylglycerides. J. Am. Oil Chem. Soc. 2012, 89 (1), 155-166.

(50) Nguyen, V.; Rimaux, T.; Truong, V.; Dewettinck, K.; Van Bockstaele, F. Granular Crystals in Palm Oil Based Shortening/ Margarine: A Review. Cryst. Growth Des. 2020, 20 (2), 1363-1372.

(51) Acevedo, N. C.; Marangoni, A. G. Toward Nanoscale Engineering of Triacylglycerol Crystal Networks. Cryst. Growth Des. 2010, 10 (8), 3334-3339.

(52) Shi, Y.; Liang, B.; Hartel, R. W. Crystal Morphology, Microstructure, and Textural Properties of Model Lipid Systems. J. Am. Oil Chem. Soc. 2005, 82 (6), 399-408.

(53) Rousseau, D.; Forestière, K.; Hill, A. R.; Marangoni, A. G. Restructing Butterfat through Blending and Chemical Interesterification. 1. Melting Behavior and Triacylglycerol Modifications. J. Am. Oil Chem. Soc. 1996, 73 (8), 963-972.

(54) da Silva, R. C.; De Martini Soares, F. A. S.; Maruyama, J. M.; Dagostinho, N. R.; Silva, Y. A.; Ract, J. N. R.; Gioielli, L. A. Microscopic Approach of the Crystallization of Tripalmitin and Tristearin by Microscopy. Chem. Phys. Lipids 2016, 198, 1-9.

(55) Edwards, R. T. Crystal Habit of Paraffin Wax. Ind. Eng. Chem. 1957, 49 (4), 750-757. 